\title{
International Sports Law Journal (2015) 15:3-4
}

\author{
Jack Anderson ${ }^{1}$
}

Published online: 21 January 2016

(C) T.M.C. Asser Instituut 2016

2015 has been a tumultuous year for sport: the Russian doping allegations in athletics and the continuing allegations of maladministration in FIFA have seen sport make the headlines for all the wrong reasons. How sport recovers in 2016 - the year of the Rio Olympics - is as of yet uncertain but will be of interest to us all.

One of the most thought-provoking articles that I read as background research on this in 2015 was a piece by an American scholar, Roger Pielke Jr., who evaluated the governance of FIFA in the context of seven discrete accountability mechanisms used by political scientists in assessing the accountability practices of political entities globally. ${ }^{1}$ These seven mechanisms are noted below and Pielke's interpretation of them can be used just to assess not only FIFA but also other international sports organisations (IAAF, UCI, etc.) who have encountered similar governance difficulties:

1. Hierarchical accountability, which typically refers to the power that superiors have over subordinates within an organization, e.g., a secretary general, president or director often has the authority to hire and fire employees.

2. Supervisory accountability, which typically refers to relationships between organizations, e.g., World Bank decisions are subject to approval by Member States.

3. Fiscal accountability, which typically refers to mechanisms of control over funding, e.g., the United Nations depends upon contributions from member states to support its activities.

\footnotetext{
Jack Anderson

jack.anderson@qub.ac.uk

1 Belfast, UK
}

4. Legal accountability, which typically refers to the requirement that international bodies and their employees must abide by the laws of relevant jurisdictions in which those laws are applicable, e.g., 25 international organizations associated with the UN are formally located in Switzerland, as well as about 250 other international organizations, and thus subject to Swiss law.

5. Market accountability, which typically refers to influence that is exercised by investors or consumers through market mechanisms, e.g., when athletes find themselves subject to scandals that call into question their ethics, such occurred when the extra-marital activities of Tiger Woods became public, sponsors have often decided to terminate their contracts.

6. Peer accountability, which typically refers to the evaluation of organizations by their peer institutions, e.g., a number of governmental and non-governmental organizations created a "dolphin-safe" label for tuna fish to put pressure on companies, governments and international organizations to harvest tuna using environmentally responsible methods.

7. Public reputational accountability which typically and in a "catch all" sense refers to the reputation of an organization among "superiors, supervisory boards, courts, fiscal watchdogs, markets and peers'.

Applying the above mechanisms to FIFA, Pielke concluded his article, originally published in 2013, by stating that "with only a few exceptions FIFA sits free from formal mechanisms of accountability that are employed to hold international organisations to account to their own

\footnotetext{
${ }^{1}$ R Pielke, "How can FIFA be held Accountable?" (2013) 16 (3) Sport Management Review 255-267.
} 
stated goals."2 The exceptions were FIFA's legal accountability to the Swiss courts and its market accountability to its sponsors. At the time of writing, Pielke further noted that neither the Swiss authorities nor FIFA's sponsors had "shown much ability or interest in shaping the governance of FIFA in a direction of reform." 3 The former changed utterly in May 2015 with the dramatic dawn raids at a hotel in Zurich leading to the arrests of several FIFA officials, a wider US Department of Justice investigation into alleged racketeering by FIFA officials and the separate investigation led by the Swiss Attorney General into allegations of criminal mismanagement and money laundering in connection with the allocation of the 2018 and 2022 World Cups.

As regards market accountability, the FIFA corruption scandal has proved so toxic that no new sponsors have joined since the 2014 World Cup, while several have left, including top "global" partners Sony and Emirates. In fact, 27 out of 34 slots for potential global sponsorship partners remain unfilled by FIFA. The loss of income has had a detrimental impact on FIFA's finances: it is projected that FIFA will make a deficit of $\$ 100$ million (€92 million) for 2015 , the first time it will have made a loss since 2001.

Nothing corrodes more quickly than the stench of corruption.

Turning to the specifics of this edition of the ISLJ, one of the principal issues is that of third-party ownership ("TPO"), as prohibited under Article 18 of the current FIFA Regulations on the Status and Transfer of Players. There are two slightly forgotten aspects of the TPO debate - both addressed in this edition. First, there is the fact that FIFA's ban on TPO encapsulates a ban both on third-party influence on clubs (Article 18bis of the FIFA Regulations prohibits any process whereby a club permits a third party to acquire the ability to influence in employment and transfer-related matters its independence, its policies or the performance of its teams) and a ban on the third-party ownership of players' economic rights (Article 18ter of the FIFA Regulations prohibits any process whereby a third party becomes entitled to participate, either in full or in part, in compensation payable in relation to the future transfer of a player from one club to another, or is being assigned any rights in relation to a future transfer or transfer compensation.)

The second slightly forgotten aspect of the TPO debate is that FIFA's prohibition has not been unanimously well received in the football family and particularly in South America and in European countries such as Spain and Portugal. The reason why the reaction to the TPO ban in such jurisdictions can be best described as "underwhelming" is assessed in Lindholm's contribution to this edition and in our new (and hopefully regular) feature - the Asser International Sports Law Blog Symposium.

Other issues of interest in this edition range from the sadly familiar (doping and racism) to the comparatively new (labour relations in sport in American college sports, in football in Croatia and Serbia and under EU fixed-term work regulations).

An interesting book review - and book reviews are always encouraged - is one which is on the topic of the independence of the Court of Arbitration for Sport. At the recent FIFPro "Legal Legends" conference held principally to commemorate, respectively, the 50th anniversary of the founding of FIFPro and the 20th anniversary of the Bosman ruling, one of the most interesting contributions was from Claudia Pechstein. Pechstein's continuing efforts, through the German courts, to question the operational integrity of the Court of Arbitration for Sport will be one of the many sports law-related proceedings to watch out for in the New Year. As befits a multi-medal winning Olympian, she is clearly a determined and resilient opponent and one who is used to winning.

Finally and as ever, I look forward to any thoughts you might have on the future direction of the International Sports Law Journal. The editorial team at ISLJ is particularly interested in ideas for special editions of the ISLJ on current topics of interest, and on an individual basis, we also especially welcome contributions from young scholars in the area of sports law. In all of the above, please do not hesitate to contact me if you wish to discuss further. For now, I hope that you enjoy the current issue.

Jack Anderson

Editor-in-Chief

International Sports Law Journal

\footnotetext{
2 Ibid, 267.

${ }^{3}$ Ibid.
} 